\title{
GOVERNANÇA E PENSAMENTO ESTRATÉGICO: UMA CRÍTICA A MICHAEL PORTER
}

\author{
Omar Aktouf \\ Professor Titular da HEC, Montreal. \\ E-mail: omar.aktouf@hec.ca
}

\begin{abstract}
RESUMO
No presente trabalho, o autor procura analisar, ou mais exatamente desconstruir, a essência do pensamento dito de "estratégia" e de governança das organizações, atualmente dominante na cena acadêmica da administração. Servindo-se de uma leitura tanto histórica, heurística, como epistemológica e metodológica da obra e do sistema dominantes no assunto, denominado por ele "porterismo", o autor faz um balanço crítico do conjunto de teorias da "estratégia" gerencial em geral e daquela do autor mais considerado no assunto: Michael Porter.
\end{abstract}

\begin{abstract}
In this essay, the author analyses, or more precisely deconstructs, the essence of thinking about "strategy" and the overall governance of organizations predominating the current academic management scene. By drawing on a simultaneously historical, heuristic, epistemological and methodological reading of the dominant work and system on this subject, which he refers to as "porterism", the author presents a resolutely critical review of the full range of theories of managerial "strategy" as well as those of the most notable author in the field, namely, Michael Porter.
\end{abstract}

\section{PALAVRAS-CHAVE}

Michael Porter, porterismo, estratégia, competitividade, vantagem competitiva.

KEY WORDS

Michael Porter, porterism, strategy, competitiveness, competitive advantage. 


\section{INTRODUÇÃO}

A infinita maximização econômica tornou-se, acompanhada da crença na corrida pela "vantagem competitiva", uma espécie de dogma, de padrão de pensamento, e de ação, em quase todos os domínios - desde negócios economia até governança e política econômica de países inteiros. Tudo parece voltado a ser estratégico e competitivo.

O porterismo tornou-se mais do que uma simples teoria, ou um decálogo de normas para o uso de gerentes que querem crer-se estratégicos. Seu modelo analítico passou a ser um molde generalizado de concepção e de análise, uma visão de mundo, uma ideologia plena e inteira. Porter é qualificado sistematicamente como o mentor dos especialistas em estratégia. Ele é ainda o autor mais citado, nos dez últimos anos, nas publicações de administração e de economia.

O modo porteriano de concepção do mundo e da economia espalha-se por todo o planeta e se enraíza nas consciências e no ensino. Mas esta maneira de ver os Estados e sociedades humanas como somente negócios agregados, voltados para o serviço da multiplicação de dinheiro, não seria ela, também e ipso facto, uma mega (ou meta) teoria da governança?

\section{MICHAEL PORTER E O PORTERISMO}

Foi no final da década de 1970 e início dos anos 1980 que o pensamento porteriano começou a influenciar os escritos, o ensino, as práticas e as consultorias em administração. Tudo começou com um artigo que imediatamente suscitou diversos admiradores. Este artigo continha o essencial de um pensamento que expandiu-se, declinando-se e conjugando-se ao gosto do sucesso que encontrou: indo do terreno do marketing ao da administração, da política empresarial à análise estratégica, e até à economia política das nações.

Michael Porter é antes de tudo um engenheiro, graduado em Princeton em 1969, em engenharia mecânica e aeroespacial. No entanto, ele completou seus estudos com um diploma de pós-graduação em business (MBA na Harvard Business School, em 1971) e depois em business economics (doutorado concluído em 1973 na Universidade de Harvard). E, desde 1973, visivelmente sem experiência alguma de campo, já poderíamos encontrá-lo como professor na Harvard Business School.

Nem tecnólogo puro, nem aclamado como cientista social, Porter é um bom representante deste pensamento aproximativo e minimalista em relação às questões do humano e do social, caracterizando bem os engenheiros tornados "gurus" da administração e que foram iniciados nas ciências ditas humanas apenas por esforços autodidatas, ao gosto de leituras heteróclitas ou pelas matérias ministradas nas "business schools".

No essencial, a obra porteriana consiste em extensões de um artigo de base publicado na Harvard Business Review: "How competitive forces chape strategy" (março/abril 1979). Encontramos nesse texto o núcleo da teoria porteriana que se desenvolverá em futuras importantes publicações: Competitive strategy: techniques for analyzing industries and competitors, em 1980; Competitive advantage: creating and sustaining superior performance, em 1985; Competitive advantage of nations, em 1990, entre outros. Porter é, desde então, apresentado como o mentor dos desenvolvimentos recentes em estratégia das organizações (da referida escola do posicionamento estratégico).

As idéias de Porter se tornaram, rapidamente, os fundamentos obrigatórios de disciplinas nos cursos de graduação e pós-graduação em Harvard. Ele é autor de 16 livros e de mais de 60 artigos publicados pelas mais prestigiosas revistas acadêmicas. Seu Competitive strategy: techniques for analysing industries and competitors (1980) foi reeditado 53 vezes e traduzido em 17 línguas; enquanto que Competitive advantage: creating and sustaining superior performance (1985) já foi reeditado 32 vezes.

Em termos gerais, o porterismo foi elaborado em três movimentos. Primeiro o da teoria do "posicionamento estratégico" com a publicação de Competitive strategy, em 1980, inspirado na economia industrial e imediatamente assimilado pelas escolas até então predominantes, ditas "da concepção" e "da planificação", com seu famoso modelo das forças competitivas. O segundo acontece com a publicação de Competitive advantage, em 1985, que consagra um dos principais pilares do porterismo: a noção de "cadeia de valores integrados". O terceiro refere-se a publicação de Competitive advantage of nations.

Não entraremos em detalhes a respeito da origem e do desenvolvimento das idéias de Porter, uma vez que este não é nosso presente objetivo. Cabe-nos apenas lembrar que essas idéias foram desenvolvidas a partir das noções de análise do setor concorrente, barreiras de entrada, estratégias genéricas, produção de valor e de cadeia de valor, de produtos de substituição, até aquelas das vantagens competitivas das nações. Contudo, pode-se ressaltar que os cavalos de batalha típicos do porterismo são as famosas estratégias genéricas das quais ele se faz apóstolo: o posicionamento por liderança em custos e o posicionamento pela diferenciação, que, como veremos, resumem-se inelutavelmente em políticas de redução massiva de mão-de-obra. 
Encontramo-nos em presença de um dos maiores limites desse sistema, uma vez que ele vai da maior solubilidade dos mercados (do nível da demanda efetiva, como diria Keynes) até um termo fixo. Vemos aqui um segundo limite histórico e teórico do porterismo: o fato dos setores, que eram original e logicamente considerados como "comparativamente vantajosos" pela teoria econômica, principalmente a partir de Ricardo, e a tradição dita ricardiana, serem setores onde os salários são os mais elevados (sinal de vigor e de produtividade do setor em questão). Sobre este ponto central, acreditamos que Michael Porter não se situa claramente em relação a nenhuma das duas grandes tradições das vantagens comparativas: a tradição smithiana e a tradição ricardiana. Ele poderia ser alinhado com a hipótese dos rendimentos decrescentes (Ricardo) ou, ao contrário, com a hipótese dos rendimentos crescentes (Smith)? Ou ainda, em última instância, com a reabilitação da tradição ricardiana, consequiência do ciclo de vida dos produtos de Vernon? O que levaria inevitavelmente à famosa abordagem dita "da doação em fatores"?

Essas questões parecem-nos terem sido totalmente rejeitadas por Porter, que em 20 páginas de seu Competitive advantage of nations não dá razão a ninguém. Seguem aqui alguns trechos de como Porter trata desses aspectos (p.10-20). Com relação a Smith e Ricardo, ele passa pela teoria das "vantagens absolutas" do primeiro, reaproxima-se da teoria das "vantagens relativas" do segundo, para recorrer a uma lógica baseada nas "diferenças inexplicáveis de clima ou de meio ambiente". Para tanto, ignora o fator "economia de escala", as diferenças de tecnologias e de produtos entre países, a não estabilidade dos fatores de produção, a circulação de mão-de-obra qualificada e dos capitais entre as nações.

Não podemos dizer que Porter esteja enganado em todos esses pontos, mas é possível denunciarmos uma falta de nuances e considerações em relação a outras teorias que apontam para as "deseconomias de escala", as barreiras de toda espécie - tarifárias, tarifárias escondidas ou não tarifárias - entre nações, mesmo consideradas em estado de "livre comércio".

Com relação a Eckscher-Ohlin e Samuelson e a questão da teoria da "doação em fatores" (sob hipótese de que a tecnologia é um fator igualmente acessível), o essencial do argumento porteriano pode resumir-se a uma vaga crítica da ignorância das "transferências internacionais entre filiais de firmas multinacionais" e de possibilidades de existência de "fatores similares entre países que comercializam entre si".

Quanto a Vernon, Porter diz exatamente (p. 18) que com suas proposições sobre o "ciclo de vida dos produtos" ele representa os balbuciamentos de uma teoria verdadeiramente dinâmica que mostra como o mercado nacional pode estimular a inovação. Mas, ao mesmo tempo, Vernon é advertido por ter negligenciado questões como: por que as empresas de determinadas nações impõem-se certas inovações? O que se passa quando a demanda emerge simultaneamente em países diferentes? Por que em um bom número de países a inovação é contínua nas indústrias nacionais?

\section{FOI NO FINAL DA DÉCADA DE 1970 E INÍCIO DOS ANOS 1980 QUE O PENSAMENTO} PORTERIANO COMEÇOU A INFLUENCIAR OS ESCRITOS, O ENSINO, AS PRÁTICAS E AS CONSULTORIAS EM ADMINISTRAÇÃO.

Como é freqüente com as teorias que pretendem impor-se como articulação entre a política, a economia e a administração, este gênero de posicionamento em relação às teorias mais gerais fica no nível dos aspectos secundários que não acrescentam nada à questão da admissão ou da refutação do argumento central dessa ou daquela concepção histórica, tornada clássica, e portanto inevitável. Este nos parece ser indubitavelmente o presente caso, com o sintético, breve e distanciado posicionamento que Porter toma diante de complexas teorias. Não há nada que nos convide, de forma sólida, a renunciar aos debates sobre as questões das vantagens (conceito pivô, se é que há um, do porterismo), sejam elas absolutas ou relativas, ou em doação de fatores, ou sob condições do ciclo de vida dos produtos, ou ainda sob hipótese de rendimentos crescentes, ou rendimentos decrescentes. De qualquer modo, o assunto mostra-se um tanto árduo para ser tratado em poucas páginas.

Porter avança dizendo que: "As teorias das trocas baseadas nas vantagens relativas são irrealistas em vários setores (...) Na maioria deles, todos esses postulados não coincidem muito com os verdadeiros dados da concorrência $(\mathrm{sic}) . .$. A teoria da vantagem relativa é igualmente frustrante para as empresas, uma vez que é distante das realidades (sic). Negligenciando o papel da estratégia da empresa (...) não é de se surpreender que a maioria dos chefes de empresas estimam que esta teoria não aborda o que lhes parece fundamental, e não oferece a orientação apropriada em matéria de estratégia" (p. 12-13). 


\section{UMA CRÍTICA}

\section{EPISTEMOLÓGICA DO PORTERISMO}

Antes, entretanto, de prosseguir em uma crítica mais pormenorizada do porterismo e da concepção de governança que o acompanha, é conveniente reconhecer que, em geral, pouco caso é feito de numerosas passagens nas quais algumas de suas tomadas de posição seriam suscetíveis de importunar o triunfo do pensamento econômico e gerencial dominantes. Ou seja, pouco se discute sobre:

- as (freqüentes) passagens onde ele enfatiza os méritos dos sistemas alemão, japonês, sueco;

- as passagens onde ele admite a não-nocividade sistemática de uma alta taxa de sindicalização ou da presença de representantes sindicais nas instâncias dirigentes das firmas destes mesmos países;

- de seu reconhecimento, via esses exemplos, do fato da intervenção do estado não ser sempre tão indesejável quanto se pretende para a economia (mesmo se ele, claro, não o diz explicitamente);

- de suas repetidas afirmações quanto à grande complexidade dos fenômenos dos quais ele trata e quanto à prudência à qual é conveniente fazer prova face a todo modelo, incluindo o seu;

- de sua convocação à desconfiança em relação às potências financeiras.

Similarmente, não nos parece que se faça grande caso de certas advertências epistemológicas indicadas por Porter, como por exemplo:

- a questão da definição do conceito de competitividade, sobre o qual ele afirma, em Competitive advantage of nations: "mais grave ainda do que a falta de consenso sobre o conceito de competitividade, é o fato de não haver nenhuma teoria amplamente aceita para explicá-la" (p. 16);

- o problema de validade da passagem das hipóteses às verificações de campo sobre as quais ele diz: "muitas explicações se fundem em postulados muito distantes da realidade (sic) da concorrência (...); tive dificuldades em fazer coincidirem a maioria dessas hipóteses com a experiência adquirida estudando e trabalhando com empresas internacionais".

A concepção porteriana situa-se, apesar das precauções tomadas, na direção exatamente oposta das teorias originais sobre o livre comércio (e.g., Smith, Ricardo, Vernon, Eckcher-Ohlin). De fato e sem nuances, o porterismo preconiza uma competitividade generalizada e uma corrida às vantagens competitivas, que não são complementares, equilibradas, visando um bem estar social recíproco, inscritas na duração, na preocupação de uma homogeneidade. Ao contrário, são egoístas, imediatistas, com um estado de espírito defi- nitivamente belicoso. Porter fala de afrontamentos, mesmo nas zonas ditas de livre comércio.

Além disso, seria indiferente que este florão do mundo econômico-administrativo contemporâneo fosse um produto típico de casamentos incestuosos entre universidades e grandes escritórios de contabilidade da região de Boston (berço fecundo dos mais célebres consultorias dos EUA)? Seria tão fortuito que este pensamento tenha decolado, como por acaso, em torno dos anos 1970, quando a indústria ocidental em geral, e a americana em particular, pareciam seguir o caminho aberto por outros sistemas econômicos - a administração sobretudo japonesa, alemã e escandinava?

No núcleo de sua argumentação, Porter comete diversos (e na nossa opinião bastante graves) erros: ideológicos, metodológicos e espistemológicos. Porter parece desconsiderar as numerosas posições, aristotélicas e pós-aristotélicas, quanto à finalidade humana da atividade econômica. Pelo menos no que se pode notar em seus escritos, Porter mostra ignorar essa questão, no que se refere às diferenças aristotélicas (mais do que fundamentais, vitais a longo prazo) entre economia e crematística ${ }^{1}$ e entre o universo econômicomonetário (ilusoriamente concebido como infinito) e o universo físico (concebido como finito).

Porter ignora também as posições de economistas ditos substantivistas, mais antropológicos (e.g., o "jovem" Marx, Karl Polanyi, Maurice Godelier); terceiro-mundistas (e.g., Celso Furtado, André GunderFrank, Samir Amin, Pierre Jalée, René Dumont, René Gendarme); mais críticos (e.g., Stuart Mill, Max Weber, John Hobson, Thorstein Veblen, Meadows e Forrester do MIT e do Clube de Roma); além de todos os marxistas e neomarxistas (de Rosa Luxemburgo a Ernst Mandel, passando por Leszlek Kolakowski até Baran e Sweezy de Chicago ou Stephen Marglin de Harvard). Pode incluir também nesta lista aqueles que compartilham de uma visão entrópica da economia (que procuram submeter o raciocínio econômico à prova da análise física da transformação de energia, como Nicolas Georgescu-Roegen, Howard Odum, Gonzague Pillet, René Passet); ou mesmo certos críticos insistentes do pensamento do "planejamento estratégico" (aparentando serem os "politicamente corretos" da administração econômica como Henry Mintberg, ou outros um pouco periféricos, mas não menos significativos, como David Knights).

Porter postula, implicitamente, como todos os economistas ortodoxos, que a acumulação e a produção de riquezas podem ser infinitas, e que a organização da sociedade que a acompanha - capitalista, definitivamente dominada pelas finanças, industrializada e neoliberal - é um constante progresso que cabe ser generalizado a todos, para a felicidade de todos. Nesse 
sentido, o lugar conferido à noção de mercado merece uma atenção mais cuidadosa. Enquanto conceito operatório pivô do conjunto do edifício econômico-administrativo dominante - especialmente da teoria da governança e da estratégia porteriana - a noção de mercado exige um desenvolvimento analítico mais aprofundado.

Tudo começou com Adam Smith. Em toda sua obra, esse pai fundador da análise econômica da sociedade utilizou exatamente duas vezes a fórmula "mão invisível", a ancestral do conceito de mercado autoregulador. Mas era preciso à ciência econômica, com os neoclássicos, um conceito menos "poético" e uma possibilidade de efetuar os cálculos desejados de forma exata, precisa, como na física. O primeiro a empenhar-se nisso foi Leon Walras. Em busca de uma solução de simultaneidade de equilíbrio entre quantidade, preços, valores, necessário ao bom funcionamento do mercado da economia "pura", Walras postulou o equivalente a uma "mecânica celeste" da sociedade (de onde as formulações pré-economistas dos problemas do equilíbrio do mercado em termos newtonianos) e a intervenção de um anunciante de preços (espécie de um equivalente ao demônio de Maxwell e do "secretário geral do mercado" de Quesnay) que anunciaria os preços de equilíbrio dos produtos e serviços, ficando neutro em relação aos pólos do jogo de gravitação entre oferta e demanda.

Isso desembocaria, mais tarde, em uma questão espinhosa: como dar conta, matemática e cientificamente, de um tal estado de simultaneidade de equilíbrios em um mercado, evitando as hipóteses embaraçosas de "mecânica celeste" e "anunciante de preços"? Foram dois prêmios Nobel de economia, Kenneth Arrow e Gérard Debreu, que atacaram esse problema. Sua conclusão é desconcertante: se existe uma solução matemática ao problema de Walras, ela é tão altamente probabilística que o estado dos equilíbrios simultâneos do mercado só podem ser um fabuloso acaso! Tão improvável quanto encontrar Buda em pessoa! Pois, explicam eles, nada permite afirmar que os mecanismos de oferta e demanda possam conduzir "naturalmente" ao equilíbrio.

O que resta, então, do conjunto edificado da estratégia da administração econômica, se retiramos a hipótese de estado de equilíbrio do mercado (central, também, ao famoso teorema de Pareto, e a tudo o que vai se seguir em termos de análises microeconômicas e econométricas)? Ou então, Michael Porter e seus inumeráveis concorrentes, teriam levado em consideração essa importante falha da teoria econômica?

Além disso, Arrow e Debreu deixam em suspenso um outro problema, o da natureza da "lei" que presidiria ao funcionamento desse fenômeno denominado mercado. A esse problema dedicaram-se duas outras celebridades da reflexão econômica contemporânea: Lypsey e Lancaster. Eles legam um teorema ainda mais desconcertante, que leva o nome deles, até então não refutado: o mercado obedece a uma espécie de lei do tudo ou nada, só é possível haver dois estados de mercado, seja $100 \%$ (caso da economia da concorrência pura e perfeita), seja $0 \%$ (caso da economia dita imperfeita).

\section{EM GERAL POUCO CASO É FEITO}

\section{DE ALGUMAS DAS TOMADAS DE POSIÇÃO de PORTER QUE DE CERTA}

\section{FORMA NUTRIRIAM O TRIUNFALISMO DO PENSAMENTO ECONÔMICO}

\section{E GERENCIAL DOMINANTES.}

No entanto, sabemos que a economia pura e perfeita é, na melhor das hipóteses, um desejo do espírito e, na pior, um delírio hiper matemático. Resta, assim, apenas uma solução: nós estamos, em qualquer que seja o caso, em situação de mercado $0 \%$ ! Então, colocam-se múltiplas questões: quem regularia esse mercado que não seria, em nenhum momento, autoregulado (o que nos levaria a reencontrar Buda)? Como podemos falar de situações de mercados progressivos ou parciais? Como justificar o que pretendem alcançar as instituições de Bretton-Woods, afirmando poder conduzir, através das medidas que elas impõem às nações, fases de etapas progressivas rumo ao estado do mercado?

Como sustentar o edifício porteriano, inteiramente construído sobre o postulado "da realidade da concorrência e das forças do mercado"? Ele jamais teria levado em conta trabalhos tão interpelantes como aqueles de Arrow e Debreu e de Lypsey e Lancaster? Ou ele considera-lhes como falsos, não pertinentes?

$\mathrm{O}$ fato é que Porter ignora tudo soberbamente, o que é grave para qualquer um que aborde a questão do futuro das nações e suas economia (e por todo intelectual que se respeita). Ignora, por exemplo, as contribuições de um movimento tão importante da historiografia contemporânea, como os Annales (e.g., Fernand Braudel), que mostra como, as vantagens adquiridas pelas nações ocidentais modernas sempre aconteceram (após a decolagem das grandes metrópoles ocidentais como Gênova, Veneza, Amsterdã até a Inglaterra e o império americano) em detrimento de regiões do Sul (colonizadas ou não). Regiões, muitas vezes, tão pilhadas, que nem conseguiam se recompor. 
Como admitir o fato de que nenhuma menção seja feita a Karl Marx e ao materialismo histórico, em uma obra que pretende explicar - ou pior, prescrever - o desenvolvimento histórico das nações? Não deveria Porter ao menos situar-se em relação a ele e explicar no que podemos desqualificá-lo antes de, implicitamente, promover o capitalismo neoliberal e suas "leis" ao estágio de realização da história?

O que queremos dizer com isso é que, ao ler Porter, trata-se de uma conduta à pretensão heurística. Tratase, primeiramente, de induzir para depois deduzir, a partir de situações limitadas e estreitamente situadas no espaço (espaço em geral americano), no tempo (pósguerra e ascensão da economia financeira da administração), na ideologia (aquela do mercado neoliberal e dos detentores de interesses financeiros, à exclusão de qualquer outro); de regras e leis com pretensões universais para a tomada de decisão e a conduta das instituições e organizações. Tudo isso indo além dos espaços, das fronteiras, das nações, das histórias, das culturas, e atualmente, indo também para além do Estado e dos serviços públicos.

Resumidamente, Porter parece utilizar as regras da influência a partir de observações empíricas bastante limitadas e à validade de generalização nula e nulamente provada: a amostragem de países selecionados para estabelecer a teoria geral da vantagem competitiva das nações incluía dez países, sobre os quais foram impostas as categorias deduzidas a partir de realidades ainda mais limitadas: as empresas dos setores industriais previamente estudados. De seu próprio consentimento, Porter transpôs, sem outra forma de processo, no nível das nações, aquilo que ele deduziu e escreveu a partir de simples casos de empresas dez anos antes.

No prefácio de Competitive advantage of nations, ele escreve: "O essencial de minha teoria repousa nos princípios de estratégia concorrencial em indústrias precisas (...) eu comecei por estudar alguns setores, alguns atores da concorrência, para em seguida voltarme para a economia como um todo" (p. 17). Em Competitive strategy: techniques for analyzing industries and competitors, ele cita, para sustentar seu desenvolvimento teórico, os casos de cerca de 30 firmas diferentes, quase todas americanas; como se somente a multiplicação de casos, submetidos à fôrma sistemática da mesma grade, constituíssem em si conhecimento científico, universalidade, validade interna e externa.

Erigir todo um edifício teórico como o de Competitive advantage of nations, sobre uma metodologia de estudos de caso de setores industriais, de firmas e grupos de firmas quase sistematicamente americanas poderia ser considerado heurístico em si? Ou ainda epistemológica ou metodologicamente legítimo, válido? Desde quando a simples descrição daquilo que convém aos interesses dominantes e o enfileiramento de indicadores de satisfação desses mesmos interesses podem servir como descrição objetiva de fenômenos ou como método científico? Podemos transformar assim os estados em comitês de gestão de interesses financeiros transnacionais e as nações em espaços voltados à competição entre gigantes do business?

Para além dessas observações gerais, destacamos aqui alguns pontos, ao nosso ver dentre os mais discutíveis e mais intelectualmente duvidosos, que caracterizam posições adotadas por Porter:

1. Como podemos, nesse início do século XXI, imaginar seriamente que nosso planeta (pelo o que parece, ao menos implicitamente, em Porter) poderia suportar seis, e em um futuro próximo, oito ou dez milhões de indivíduos, todos vivendo pelo crescimento máximo, todos em competição contra todos, e atingindo níveis de vida comparáveis àqueles dos mais ricos?

2. As nações e os estados, e suas políticas econômicas, podem ser organizados institucional, intelectual, ética, moral, social e politicamente da mesma forma que uma empresa, seja ela qual for? Poderia o State-business ser uma categoria de pensamento ou um fundamento de ação coletiva sustentável? Ou mesmo um tipo ideal teoricamente formulável? Os objetivos dos estados ou das nações são redutíveis às pesquisas de vantagens, de ganhos, de aproveitamento (tudo isso podendo ser reunido como eficiência) concebidos em termos de indicadores de rentabilidade econômica, de concorrência, de conquistas de fatias de mercado?

3. O simplismo caricatural (como é candidamente admitido por Porter em prefácio) do modelo do "losango a quatro variáveis" pode dar conta da enorme complexidade (isso também candidamente admitido por Porter) de fatos e processos reais de que falamos? Senão, por que continuar a fazer como se pudéssemos assegurar previsões, formulações, planificações e decisões estratégicas com conhecimento de causa, a partir da aplicação desse modelo?

4. A mundialização da economia, de que tanto ouvimos falar, não teria nada a ver com a fase imperialista do capital, a fase neocolonialista da geopolítica do pós-guerra? Coisas que os neomarxistas trataram abundantemente desde Rosa Luxemburgo e Lênin até Samir Amin, e mesmo os não marxistas como John Hobson ou Galbraith? Podemos assim ignorar essas teorias que apresentam a generalização do sistema econômico do tipo capitalista à escala do planeta, não como uma inelutável graça para todos, mas como uma calamidade tendo por motor as guerras e a pressão sem fronteiras das contradições históricas do capitalismo (realização exterior 
de mais valia, pesquisa exterior de mercados, acumulação sempre concentrada de capital, defasagens entre o discurso da superestrutura produtora das ideologias e a realidade vivida no centro da infraestrutura)? Se substituíssemos o termo "mundialização" por "imperialismo" ou "neocolonialismo", toda análise porteriana não seria mais do que afirmações ideológicas parciais infundadas? Todas as contas feitas, Porter não faz mais do que uma descrição da forma de funcionamento da economia, tal qual desejam as classes dominantes.

5. Podemos negligenciar, ignorar, rejeitar todas as análises dos terceiro-mundistas e não considerar os fenômenos como os dualismos que afetam os países em desenvolvimento, desde o início da era colonial (cisão em dois setores antagônicos: um dito "moderno", minoritário, ocidentalizado, freqüentemente corrompido e mafioso e um outro dito "tradicional", majoritário, desestruturado, empobrecido, deixado pelos exploradores)? Não fazer caso algum da desigualdade crescente na evolução dos termos de comércio entre norte e sul? Da polarização do planeta em centros que concentram, absorvem o capital sem cessar e em periferias que pagam o preço por essa absorção? Dos efeitos da dolarização da economia mundial? Do comportamento predador, devastador das multinacionais? Podemos seriamente fazer a hipótese de que a dominação de fato, que nos vivemos cada vez mais todos os dias, da economia planetária pelas transnacionais possa favorecer a concorrência e a competitividade? E não mais a concentração, as mega fusões, os monopólios, os oligopólios? Ou então é preciso recorrer a uma dessas fraudes semânticas das quais os economistas têm o segredo, do gênero "concorrência monopolizada"?!

6. Isso seria também facilmente, ainda, compatível com uma posição aberta em favor do tão aclamado livre comércio? Quais livres comércios podemos imaginar entre regiões como os Estados Unidos ou a União Européia? Onde estão as homogeneidades (sociais, culturais, tecnológicas, econômicas) que supõe os benefícios respectivos que teríamos o direito de esperar em se tratando de países em livre comércio? Este foi o caso, notadamente para o México, quando foi decretada uma zona de livre circulação de fatores como a NAFTA (North America Free Trade Agreement)? Quem pode ainda sustentar que isso tenha feito algum bem para os mexicanos? Ou mesmo, salvo os ambientes de negócios e os empresários, para o Canadá?

7. O livre comércio, tal qual pode ser concebido no sistema porteriano, seria somente essa espécie de corrida à dominação do outro, chamada "competi- tividade", supondo unicamente rivalidades e lutas, em uma mundialização concebida antes de tudo como uma expansão, desde as fronteiras nacionais até todo o planeta, campos de batalha entre firmas? Tudo a partir do modelo americano?

8. A lógica financeira maximalista do mercado autoregulado do capitalismo no estilo americano é equiparada àquela do "mercado social regulado pelo Estado", do capitalismo industrial no estilo alemão ou japonês? Entretanto, Porter cita em abundância, e toma indistintamente como exemplos, empresas americanas, inglesas, suecas, alemãs e japonesas.

\section{A CONCEPÇÃO PORTERIANA}

\section{SITUA-SE NA DIREÇÃO EXATAMENTE OPOSTA DO ESPÍRITO DAS TEORIAS}

\section{ORIGINAIS SOBRE O LIVRE COMÉRCIO.}

9. O termo "vantagem", em si, não é um conceito neutro. Sobretudo quando sabemos o quanto o jogo é desigual entre países ricos e aqueles ditos em desenvolvimento, entre países produtores de matériaprima e outros detentores de alta tecnologia, entre todas as potências multinacionais e estados de terceiro mundo. Ou seja, quando sabemos a diferença imensa entre (a) as condições iniciais que permitiram a decolagem econômica do ocidente no século XVII (revolução técnica e superprodução agrícola, cooperativas comerciais exteriores e colonizações como alavancas financeiras) e (b) as condições atuais a partir das quais demanda-se aos países de terceiro mundo fazer sua própria decolagem (agriculturas anêmicas ou prejudicadas, mercados interiores desarticulados, produções voltadas para exportação e natureza devastada).

10. Como podemos, apoiando-se em Porter, formular a hipótese de que esta arena mundial denominada "mercado" seja uma espécie de laboratório transparente, limpo e asséptico, onde os jogadores são todos honestos, iguais diante das instâncias internacionais, uma vez que se contabiliza apenas as "vantagens" advindas da bondade da natureza, da providência (tradição das vantagens ante facto da doação em fatores), das capacidades produtivas que os esforços e a engenhosidade de empreendedores nacionais souberam desenvolver (tradição das vantagens ex post sobre hipótese de rendimentos crescentes)? Michael Porter sonha com um mundo sem corrupção, sem corruptos, sem máfias, sem potências financeiras, políticas e militares que manipu- 
lam todos os mercados de todos os produtos, todos os comércios. Seria ingenuidade? Porter estaria enganando a si mesmo? Senão, a quem ele acredita estar enganando, ainda que chegue a fazer alusão aqui e ali aos "interesses" de "coalizões" que poderiam disfarçar os jogos do mercado (por ele, tratase neste caso sobretudo do estado regulamentador inimigo das forças do mercado)?

\section{Podemos FAZER POUCO CASO}

\section{DO COMPORTAMENTO PREDADOR,} DEVASTADOR DAS MULTINACIONAIS?

11. Porter ignoraria um fenômeno, considerado há muito tempo como central na análise do ambiente em administração e denominado enactment? Fenômeno que leva a projetar (desde o ponto de vista e dos interesses daqueles que analisam) tantas características no ambiente analisado que acabamos por realmente enxergá-las. Isso sem falar das transformações inevitáveis que provocaram todo o "estudo setorial", em qualquer ambiente, a partir do momento em que essa análise dava lugar a estratégias e a implantações de decisões. Então, não é mais o ambiente que faz a estratégia corporativa, é o inverso! Aliás, esta é uma discussão que já foi seriamente abordada, ilustrada, confirmada. Exemplos concretos e edificantes apoiaram-na, há mais de trinta anos por John Kenneth Galbraith em $O$ novo estado industrial.

12.Um instrumento como o PNB (Produto Nacional Bruto) é, em todas as suas formas, tomado com indicador privilegiado (exatamente sete vezes entre os 16 critérios colocados em Competitive advantage of nations). Michael Porter estaria ignorando as numerosas e severas críticas endereçadas a este indicador macroeconômico que, segundo vários especialistas, não queria mais dizer nada?

13. Os PNB, PIB (Produto Interno Bruto) e outros indicadores de competitividade de toda espécie não apresentariam contradições imperdoáveis, uma vez que citamos países como Japão, Alemanha, Suécia, Dinamarca como exemplos de conquistas (competitivas) situando-se em uma ideologia e uma óptica das políticas econômicas, industriais e sociais no estilo americano, ou seja, no pólo exatamente oposto daquilo que fazem esses países? Michael Porter proclama-se resolutamente neoliberal, enquanto que esses países são, a todos os olhares, tudo menos neoliberais! São social-democratas, com uma economia "social de mercado", guiada pelo estado. Isso não interferiria em nada para seu sucesso? E isso poderia ser integrado sem nuanças ao modelo porteriano?

14. O que dizer da hipótese, implícita mas onipresente, de que os ganhos de uns nunca são as perdas dos outros. Isso não seria mais aplicável aos países mais frágeis e não industrializados, em relação à perda nítida e total, cumprida de forma dramática, sobre o plano ecológico?

15.A noção de "clusters industriais", espécie de epicentro do modelo porteriano, parece estranha a certos conceitos como o de "pólos de desenvolvimento", elaborado por François Perroux, ou o de complexos "de indústrias-industrializantes", levado a diante por Estanne De Bernis. Sem falar da analogia com as redes da indústria japonesa. Tudo isso, sustentaria infinitamente mais cooperação do que competição, mais intervencionismo e de presença do estado do que de laisser-faire, mais diálogo do que concorrência, mais colaboração mútua do que lutas de enfrentamento entre firmas e nações. Tudo, absolutamente tudo, desde o papel do estado e o contexto intra e inter-empresas, opõe, por exemplo, as redes inter-organizacionais do tipo japonês ao que Porter apresenta como os clusters. Como uns e outros podem preencher o mesmo ofício competitivo para as respectivas nações? Mas é verdade que também aqui, nem Perroux, nem De Bernis estão situados em seus contextos ideológi$\cos$, nem situados em relação às proposições sobre os clusters, ainda que Porter os mencione na bibliografia.

16. Enfim, ao exemplo de David Knight, e em pleno acordo com ele, podemos constatar na obra porteriana as inadmissíveis falhas científicas e epistemológicas seguintes:

- Um positivismo excessivo pela aplicação de cânones do método dito científico duro, próprio das ciências da natureza e do inerte (e.g., biologia, física), a um objeto não inerte, proveniente de decisões e interações humanas, advindo natural e "ontologicamente" dos atos de administração, de planificação, e mesmo estratégicos.

- Uma objetivação-reificação excessiva das organizações e dos dirigentes, tratando-lhes como sujeitos ativos e como objetos do mesmo estudo dos mecanismos de definições, planificações, seleções e estratégias.

- Um recurso a inumeráveis atalhos heurísticos que consistem em transportar as reivindicações ideológicas e as representações mentais oriundas de uma elite dominante à caracterização, pretendida objetiva e universal, das realidades econômicas e organizacionais.

- Uma projeção sistemática do modelo de Harvard (modelo construído pela tradicional interação des- 
sa Universidade com os grandes escritórios de consultoria da região de Boston) na sua pretendida teorização dos mecanismos da estratégia das vantagens competitivas.

- Uma fusão entre problemática de sua própria construção teórica e o objeto mesmo dessa teoria, a saber, posicionar as empresas a priori como lugar das vantagens competitivas, para em seguida partir para a pesquisa de suas vantagens competitivas.

- Uma simbiose entre a arquitetura de sua teoria e os serviços que podem entregar os escritórios de consultoria com os quais ele e Harvard sempre estiveram em parte ligados. A única escolha é recorrer aos porterianos como consultores, uma vez que se admite sua teoria. $\mathrm{O}$ que pode legitimamente levar a pensar que essa teoria foi montada oportunamente e sustentada para servir a esses fins.

- Uma pretensão declarada à capacidade de controlar o ambiente, os concorrentes, o Estado, o futuro, as incertezas, através do uso de meios puramente positivistas, promovidos ao status de infalibilidade científica universal e transcultural.

- Uma omissão, com consequiências incalculáveis, da seguinte evidência: se as empresas aplicassem efetivamente os princípios das vantagens competitivas e estivessem obtendo sucesso, mais ninguém poderia pretender recorrer a tais vantagens; a teoria chegaria a uma auto-destruição em decorrência de sua generalização.

- Uma grave confusão entre as representações mentais positivistas que Porter faz da administração e da realidade gerencial tal que ela se apresenta dentro do que ele pretende apresentar como "a verdadeira via".

- Uma omissão não menos grave do peso, por toda parte necessário e inevitável, da intervenção dos meios detentores do poder, particularmente em todos os fenômenos tratados por ele. Omissão que deixa supor que os jogos competitivos poderiam dar-se em um mundo tão neutro quanto igualitário e cientificamente objetivo.

- Uma construção de problemas estratégicos e gerenciais onde a teoria porteriana é "a" solução. Assim, no conjunto do edifício, desfila uma flagrante tautologia: os problemas colocados são diretamente aqueles pelos quais a teoria porteriana é feita. É propriamente uma atitude anticientífica.

Poderíamos continuar ainda por muito tempo a lista de reprovações (graves, devemos admitir, freqüentemente intelectual e academicamente inaceitáveis) que podem ser endereçadas ao conjunto da teoria porteriana.

Pensamos ter conseguido aqui, ao menos, dar ao leitor uma pequena idéia das falhas que podem lesar partes inteiras do pensamento econômico-gerencial dominante atual, marcado particularmente pela moda da governança e da estratégia corporativa. Elas próprias dominadas pelos trabalhos de Michael Porter e seus incontáveis seguidores.

\section{PORTER SIMPLESMENTE}

NOS CONDUZ A FAZER A

\section{MACROECONOMIA DEPENDER}

\section{DA MICROECONOMIA E AS POLÍTICAS NACIONAIS DAS DECISÕES DE NEGÓCIOS!}

Como admitir, sem questionamento, que gerações inteiras de estudantes em administração sejam formados, freqüentemente sem nenhuma capacidade de reflexão crítica, nem distanciamento, a pensar segundo o modelo elaborado por Porter? Que programas inteiros de gestão, dita estratégica, sejam quase inteiramente baseados, sem discernimento, nas construções porterianas? Isso não revelaria mais uma opinião ideológica preconcebida do que objetividade científica?

\section{CONCLUSÕES}

Trata-se, em todo o movimento do estrategismo ao modo de Porter - combinado a uma forma, consciente ou não, de concepção pós-moderna (no sentido do pósmodernismo ontológico e não metodológico) do socialeconômico - de um universo em constante elevação em direção à abstração. Os "metagerentes" (estratégias) gerando os "gerentes" os quais, eles mesmos, geram discursos abstratos que absorvem o real: os discursos redutores das finanças, da microeconomia, da gestão da produção, dos recursos humanos, etc. Há em tudo isso uma espécie de hold-up conivente onde as boas e velhas noções de dialética, contradições, exploração, falsa consciência, dominação de termos da troca são substituídos por noções bem mais neutras, como a reflexividade, o conhecimento ordinário, a hipótese de simetria dos poderes, a competitividade (conceito comodamente oportuno para evacuar qualquer idéia de dominação ou de exploração já que o mais fraco é exposto como aquele que não sabe usar suas vantagens competitivas).

Referimo-nos à fuga em direção à abstração no sentido de fuga do terreno concreto das relações sociais onde o econômico é o determinante por excelência, fuga 
onde se constrói o social, quase que unicamente, "na cabeça e representações mentais das pessoas". Seria como se a história - via o comportamento estratégico das firmas e das nações - se produzisse sob uma forma de determinismo "ao modo de Hegel", encarnando a evolução da socio-economia por um tipo de "razão estratégica" quase imanente. Como se nunca, entre outros, qualquer um como Karl Marx pudesse estar intensamente empenhado em recolocar Hegel em seu lugar!

Como conseqüência desse hold-up e de suas implicações, Michael Porter pode permitir-se anunciar no prefácio de seus principais livros que simplesmente não há definições satisfatórias de noções tão centrais como aquelas de competitividade e de valor. Tanto é que ele construiu toda sua teoria apoiando-se nestas duas noções!

Como podemos avançar tão alegremente (como se numerosos grandes economistas já não tivessem várias vezes se debruçado sobre esta questão) sobre o perigoso terreno do problema do "valor", como o fez Michael Porter, sem nenhuma definição conveniente? Com tais hold-up e enganos epistemológicos habilmente conduzidos, é fácil propor desenvolvimentos pseudo-intelectuais, onde a sedução diante do público do mundo de negócios dá as mãos ao simplismo e a trivialidade do proposto.

Fazendo do planeta um vasto campo de batalha pela infinita competitividade, sob a única obrigação de maximização de lucros e dividendos de firmas colocadas como a finalidade histórica das nações, Porter simplesmente nos conduz a submeter a macroeconomia a uma dependência da microeconomia e as políticas nacionais das decisões empresariais! O tratamento da economia é concebido somente em curto prazo e em agravamento exponencial de desequilíbrios, já desastrosos, entre norte e sul e entre os próprios fatores de produção (capital, trabalho e natureza).

Submetamos, finalmente, a lógica porteriana a seus limites: uma vez nosso planeta tornado competitivo pela graça dos losangos e diamantes porterianos, teremos direito a uma teoria da competitividade interplanetária ou intergaláctica? A uma teoria das vantagens competitivas das galáxias? $\bigcirc$

\section{NOTA DO TRADUTOR \\ 1. A crematística é de uma parte da economia que trata da produção das riquezas. Na doutrina de Aristóteles, a \\ produção da riqueza no intuito da acumulação indefinida é egoísta. Opõe-se então ao econômico, entendido por \\ Aristóteles como a acumulação de riquezas para o bem- estar da comunidade.}

\section{REFERÊNCIAS BIBLIOGRÁFICAS}

AKTOUF, O. Corporate culture the catholic ethic and the spirit of capitalism: A Quebec experience. In: organizational symbolism. Berlin, New York: Barr A Turner, Walter de Gruyter, Eds., 1990. p. 43-53.

AKTOUF, 0 . Theories of organizations and management in the 1990's: towards a critical radical humanism?. Academy of Management Review, vol. 17, n 3 , p. 407-431, 1992

AKTOUF, O. Post-mondialisation, économie et organisation: stratégie de l'autruche rationnelle? Montréal et Paris : Écosociétés et La Découverte, à paraître, 2001.

ALBERT, M. Capitalisme contre capitalisme. Paris Éditions du Seuil, 1991.

ALVESSON, M.; SKOLDBERG, K. Reflexive methodology. London: Sage, 2000.

AMIN, S. L'accumulation à l'échelle mondiale. Paris Anthropos, 1971.

AMIN, S. L'empire du chaos: la nouvelle mondialisation capitaliste. Paris : I'Harmattan, 1991.

ARISTOTE. Éthique à nicomaque. Paris : Béatrice Nauwlaerts, 1970, 2 vol.
ARISTOTE. Politique : livre I à VIII. Paris : Gallimard, 1993.

ARROW, K. J. General equilibrium. Cambridge : Belknap Press, 1983.

ATTALI, J. L'économie de l'apocalypse. Paris : Seuil, 1995.

BARAN, P.A.; SWEEZY, P.M. Monopoly capital. New York : Monthly Review Press, 1966.

BERTHOUD, A. Aristote et l'argent. Paris : F. Maspéro, 1981.

BOUCHIKHI, H. Structuration des organisation. Paris : Economica, 1990.

BRAUDEL, F. Civilisation matérielle, économie et capitalisme, les jeux de l'échange. Paris: Armand Colin, 1980, 3 vol.

BRAVERMAN, H. Labor and monopoly capital. New York: Monthly Review Press, 1974.

BROWN, L.R. State of the world 1990. Washington : Worldwatch Institute, 1990.

BUCHANAN, J.M.; TOLLISON, R.D. The theory of the public choice. University of Michigan Press, 1984.
CHANLAT, A., DUFOUR, M. et al. La rupture entre I'entreprise et les hommes. Paris et Montréal : Édition de I'organisation et Québec Amérique, 1985.

CHOSSUDOVSKY, M. La mondialisation de la pauvreté. Montréal : Écosociété, 1998.

COURVILLE, L. Piloter dans la tempête: comment faire face aux défis de la nouvelle économie. Montréal Québec: Amérique et Presses de l'École des HEC, 1994.

DE BERNIS, G.D. Théories économiques et fonctionnement de l'économie mondial. Grenoble: Presses universitaires de Grenoble, 1988

DEBREU, G. General equilibrium theory. Cheltenham: E. Elgar, 1966.

DÉRY, R. Topographie du champ de recherche en stratégie d'entreprise. Management International vol. $1, \mathrm{n}^{\circ} 2$, p. 11-18, 1997.

DÉRY, R. La structuration socio-historique de la stratégie. In: Noël, A. et al., Perspectives en management stratégique. Paris : Economica, 1997. p. 15-63.

DUMONT, R. Un monde intolérable. Le libéralisme en question. Paris : Seuil, 1988. 
ENGELS. F. Origine de la famille de la propriété et de l'État. Paris : Éditions Sociales, 1961.

FORRESTER, J. W. World dynamic. Cambridge : Wright-Allen Press, 1971.

FRANK, A.-G. Le développement du sousdéveloppement. Paris: Maspéro, 1967.

FURTADO, C. Development and underdevelopment. Berkeley: University of California Press, 1964.

GALBRAITH, J.K. Economics in perspective. A critical history. Boston : Hougton Mifflin, 1987.

GALBRAITH, J.K. Voyage à travers le temps économique. Paris : Seuil, 1989.

GEORGESCU-ROEGEN, N. The entropy law and the economic process. Cambridge : Harvard University Press, 1971.

GIDDENS, A. La constitution de la société: éléments de la théorie de la structuration, Paris : PUF, 1987

GODELIER, M. Rationalité et irrationalité en économie. Paris : Maspéro, 1966.

GROUPE DE LISBONNE. Les limites de la compétitivité. Montréal : Boréal, 1995.

HAFSI, T.; SÉGUIN, F.; TOULOUSE, J.M. La stratégie des organisations: une synthèse. Éd. Transcontinental inc. 2000.

HEILBRONER, R. The wordly philosophers. New York: Washington Square Press, 1970.

HEILBRONER, R. Marxism: for and against. New York: W.W. Norton and Company, 1980.

HOBSON, J.A. Imperialism. Michigan : University of Michigan Press, 1965

JACQUARD, A. J'accuse l'économie triomphante. Paris : Seuil, 1995.

JALÉE, P. Le pillage du tiers monde. Paris : F. Maspéro, 1965.

JONES, E.L. The european miracle. Cambridge : Cambridge University Press, 1987.

KNIGHTS, David. Changing spaces: the disruptive impact of a new epistemological location for the study of management, 1992.

KOLAKOWSKI, L. Histoire du marxisme, vol. 2. Paris: Fayard, 1987.
LUXEMBOURG, R. L'accumulation du capital. Paris : F. Maspéro 1967.

MALABRE, A.L. jr. The lost prophet: an insider's history of the modern economists. Boston : Harvard Business School Press, 1994.

MARIS, B. Lettre ouverte aux gourous de l'économie qui nous prennent pour des imbéciles. Paris : Albin Michel, 1999.

MC CLOSKEY, D. "Bourgeois Virtue », American Scholar, vol. 63 (2), p. 177-191, printemps 1994.

MINC, A. Capital.France.com. Paris : Seuil, 2000.

MINTZBERG, H. The rise and fall of strategic planning. New York : The Free Press, 1994.

MORGAN, G. Images of organizations. Beverly Hills: Sage Publications, 1986.

NAHREMA, M.; BAWTREE, V. (Éd.). The postdevelopment Reader. London \& New Jersey : Zed Books, 1997.

NORTH, D.C. «Institutions 》, The Journal of Economic Perspectives, vol. 5 (1), p. 97-112, 1991.

NOVAK, M. The catholic ethic and the spirit of capitalism. New York : Free Press, 1993.

ODUM, H. PILLET, G. E3 : énergie, écologie, économie. Genève: Georg, 1987.

OLSON, M. The logic of collective action. Boston: Harvard University Press, 1965.

OHLIN, B. Interregional and international trade. Boston : Harvard University Press, 1967.

PASSET, R. L'économique et le vivant. Paris : Payot, 1979.

PERROUX, P. Pôles de développement ou nations. Paris : PUF, 1958

POLANYI, K.; ASENBERG, C. Les systèmes économiques dans I'histoire et dans la théorie. Paris : Larousse, 1960.

PORTER, M. Stratégie : analysez votre industrie. Harvard L'Expansion, 1979.

PORTER, M. How competitive forces shape strategy. Harvard Business Review, 1979.

PORTER, M. Competitive strategy: techniques for analyzing industries and competitors. New York : Free Press, 1980.

PORTER, M. Competitive advantage: creating and sustaining superior performance, 1985.
PORTER, M. The competitive advantage of nations. New York : Free Press, 1990.

PORTER, M. L'avantage concurrentiel des nations. Paris : Interéditions, 1993.

PUTTERMAN, L. The economic nature of the firm, $A$ Reader. Cambridge : Cambridge University Press, 1986. p. $72-85$.

QUESNAY, F. Tableau économique des physiocrates. Paris : Calmann-Lévy, 1969

RICARDO, D. Des principes de l'économie politique et de l'impôt. Paris : Flammarion, 1992.

RIFKIN, J. Entropy, a new world view. New York Bentam Books (édition révisée), 1989.

SAINT-MARC, P. L'économie barbare. Paris : FrisonRoche, 1994.

SALONER, G.; SHELPARD, A.; PODOLNY, J. Strategic Management. Whiley \& Sons, 2000.

SAMUELSON, P.A.; STOPER, W.F. « Protection and real wages », Review of Economic Studies, vol. 9, 1941, p. 58-73.

SCHUMPETER, J. Capitalism, socialism and democracy. New York : Harper and Brothers, 1942.

SMITH, A. Enquête sur la nature et les causes de la richesse des nations. Paris : Presses universitaires de France, 1995.

VEBLEN, T. Théorie de la classe de loisir. Paris: Gallimard, 1970.

VERNON, R. Les entreprises multinationales: la souveraineté nationale en péril. Paris : Calmann-Lévy, 1973.

WALRAS, L. Éléments d'économie politique pure théorie de la richesse social. Paris : Librairie générale de droit et de jurisprudence, 1952.

WEBER, M. Économie et société. Paris : Plon, 1971.

WEBER, M. Histoire économique. Paris : Gallimard, 1991.

WEITZMAN, M.L. The share economy: conquering stagflation. Cambridge : Mass, Harvard University Press, 1984.

WILLIAMSON, O.E. « Strategizing, economizing, and economic organization », Strategic Management Journal, vol. 12, p. 75-94, 1991

WOLMAN, W.; COLAMOSCA. A. The judas economy. The triumph of capital and the betrayal of work. Massachussetts : Addison-Wesley, 1998. 